Int. J. Electrochem. Sci., 13 (2018) $6756-6770$

\title{
Au@Ag Core-shell Nanoparticles Supported on Carbon Nanotubes as Promising Catalysts for Oxygen Electroreduction
}

\author{
$\mathrm{Na} \mathrm{Li}{ }^{1,2}$, Changhong Wang ${ }^{*}, 1$, Tingzhen $\mathrm{Li}^{1,2}$, Brendan Latimer $^{3}$, Zhen Liu ${ }^{3}$ and Zhenghua Tang ${ }^{*, 2,4}$ \\ ${ }^{1}$ School of Materials and Energy, Guangdong University of Technology, Guangzhou, 510006, P. R. \\ China. Email: wangchh@gdut.edu.cn \\ ${ }^{2}$ Guangzhou Key Laboratory for Surface Chemistry of Energy Materials, New Energy Research \\ Institute, School of Environment and Energy, South China University of Technology, Guangzhou \\ Higher Education Mega Centre, Guangzhou, 510006, P. R. China. Email: zhht@ scut.edu.cn \\ ${ }^{3}$ Department of Physics \& Engineering, Frostburg State University, Frostburg, MD 21532-2303, \\ United States \\ ${ }^{4}$ Guangdong Provincial Key Laboratory of Atmospheric Environment and Pollution Control, \\ Guangdong Provincial Engineering and Technology Research Center for Environmental Risk \\ Prevention and Emergency Disposal, School of Environment and Energy, South China University of \\ Technology, Guangzhou Higher Education Mega Centre, Guangzhou, 510006, P. R. China \\ *E-mail: zhht@scut.edu.cn
}

doi: $10.20964 / 2018.07 .01$

Received: 16 February 2018 / Accepted: 15 April 2018 / Published: 5 June 2018

Bimetallic nanoparticles with core-shell structure usually demonstrate enhanced catalytic performance due to the lattice strain created between the core and the shell region. The Au@Ag core-shell nanoparticles with different Au-to-Ag molar ratios were firstly fabricated by a facile method under mild conditions, and the $\mathrm{n}(\mathrm{Au}): \mathrm{n}(\mathrm{Ag})=1: 2$ sample showed the best electrocatalytic activity toward oxygen reduction reaction (ORR), a key reaction which plays an important role in fuel cells and metal-air batteries. Subsequently, the Au@Ag nanoparticles of $n(A u): n(A g)=1: 2$ were loaded on carbon nanotubes to prepare nanocomposite catalysts with different metal mass ratios of $20 \%$ $\mathrm{Au} @ \mathrm{Ag} / \mathrm{CNTs}, \quad 30 \% \quad \mathrm{Au} @ \mathrm{Ag} / \mathrm{CNTs}, \quad 40 \% \quad \mathrm{Au} @ \mathrm{Ag} / \mathrm{CNTs}$, and 50\% Au@Ag/CNTs. The characteristics of the as-synthesized nanocomposites were examined by transmission electron microscopy (TEM), X-ray diffraction (XRD) and X-ray photoelectron spectroscopy (XPS) as well. The nanocomposites demonstrated effective electrocatalytic performance toward ORR. Electrochemical tests showed that the 30\% Au@Ag/CNTs sample exhibited the highest activity among the series, in aspects of onset potential and kinetic current density. Furthermore, the sample of $30 \%$ $\mathrm{Au} @ \mathrm{Ag} / \mathrm{CNTs}$ exhibited markedly higher long-term stability than Pt/C. The results clearly illustrate that the Au@Ag core-shell nanoparticles-based nanocomposites hold great potentials as efficient ORR catalysts for fuel cell applications. 
Keywords: Au@Ag core-shell nanoparticles; Carbon nanotubes; Nanocomposite catalyst; Oxygen reduction reaction; Fuel cell

\section{$\underline{\text { FULL TEXT }}$}

(C) 2018 The Authors. Published by ESG (www.electrochemsci.org). This article is an open access article distributed under the terms and conditions of the Creative Commons Attribution license (http://creativecommons.org/licenses/by/4.0/). 